\title{
LECTURERS' PERFORMANCE IN INCREASING OF LEARNING QUALITY THROUGH SELF-MONITORING EVALUATION
}

\author{
Andi Rahman \\ Universitas PGRI Palembang, Sumatera Selatan, Indonesia \\ Email: andiplg25@gmail.com \\ DOI: 10.35445/alishlah.v12.i2.303 \\ Accepted: November $30^{\text {th }}, 2020$. Approved: December $22^{\text {nd }}, 2020$ \\ Published: December $30^{\text {th }}, 2020$
}

\begin{abstract}
The research objective was to get the use of teachers' self-monitoring strategies in conducting performance evaluations, so that the quality of learning in class becomes high quality. The research method used descriptive qualitative. Data collection techniques used observation and interviews. The data analysis technique consists of three stages, namely data reduction, data presentation, and drawing conclusions. The research was conducted at the Ahmad Dahlan Institute of Technology and Business Jakarta. The results showed that the teacher always evaluated the performance of the learning and teaching process on a regular basis, namely at the end of each semester. This is done to evaluate the overall learning outcomes. Meanwhile, learning evaluation is also carried out after each learning process by students' input. The implication of the research results is the development of a teacher's performance evaluation system at the University, either carried out by individual or university leaders.
\end{abstract}

Keywords: Performance, Learning, Self-Monitoring

\section{EVALUASI KINERJA DOSEN DALAM MENINGKATKAN KUALITAS PEMBELAJARAN MELALUI STRATEGI PEMANTAUAN DIRI}

\begin{abstract}
Abstrak
Tujuan penelitian adalah untuk mendapatkan penggunaan strategi pemantauan diri dosen dalam melakukan evaluasi kinerja, sehingga kualitas pembelajaran di kelas menjadi berkualitas. Metode penelitian menggunakan kualitatif deskriptif. Teknik pengumpulan data menggunakan observasi dan wawancara. Teknik analisis data terdiri dari tiga tahap yaitu reduksi data, penyajian data, dan
\end{abstract}


Al-Ishlah: Jurnal Pendidikan - ISSN: 2087-949o (p); 2597-940X (e)

Vol. 12, No. 2 (2020)

penarikan simpulan. Penelitian dilakukan di Institute Teknologi dan Bisnis Ahmad Dahlan Jakarta. Hasil penelitian menunjukkan bahwa dosen selalu melakukan evaluasi kinerja untuk hasil proses pembelajaran dan pengajaran secara berkala yaitu setiap di akhir semester. Hal ini dilakukan untuk mengevaluasi secara keseluruhan hasil belajar. Sedangkan evaluasi pembelajaran juga dilakukan setiap selesai melakukan proses pembelajaran dengan meminta masukkan dari para mahasiswa. Implikasi dari hasil penelitian adalah pengembangan pada sistem evaluasi kinerja dosen di Universitas baik yang dilakukan oleh dosen masing-masing ataupun pimpinan Universitas.

Kata Kunci: Kinerja, Pembelajaran, Self-Monitoring

\section{PENDAHULUAN}

Kinerja menjadi kunci utama bagi keberhasilan upaya seseorang ataupun organisasi mencapai tujuan. Kinerja sebagai bentuk pelaksanaan tugas dalam situasi yang memungkinkan hasil kerja yang optimal. Jadi kinerja akan menjadi lebih maksimal ketika didukung oleh kondisi atau situasi kerja yang baik. Seseorang akan memiliki tingkatan kinerja yang lebih baik jika mendapatkan pengaruh dari situasi atau lingkungan kerja yang kondusif, nyaman, dan fleksibel. Bagi seorang pendidik, kinerja yang baik tentunya tercapaianya tujuan pembelajaran yang telah ditetapkan sehingga kualitas pendidikan bisa berhasil menghadapi segala tantangan dan menghasilkan lulusan yang mumpuni di era global saat ini.

Tuntutan pendidikan berkualitas menjadi keharusan bagi para dosen di tingkat pendidikan tinggi. Apalagi pada kondisi pandemi Covid-19 dimana proses pembelajaran telah beralih pada sistem pembelajaran daring. Hal ini tentunya memberikan suatu pemahaman kepada para dosen bahwa kegiatan pembelajaran daring harus dirasakan seperti kegiatan pembelajaran tatap muka dan tetap berkualitas dengan media perangkat teknologi. Setiap dosen harus membangun strategi pengajaran dengan sangat tepat dan memberikan suasana belajar yang nyaman bagi mahasiswa. Selain itu, dosen juga harus melakukan evaluasi diri terhadap hasil proses belajar mengajar yang telah dilakukan. Praktik mengevaluasi kinerja sendiri atau kinerja orang lain ada di mana-mana baik di tempat kerja dan pengaturan kelembagaan yang merupakan dasar dari upaya peningkatan kualitas pendidikan (Skovholt, Nordenström, \& Stokoe, 2019). Kegiatan evaluasi pembelajaran merupakan salah satu bentuk evaluasi kinerja dosen untuk meningkatkan kualitas pembelajaran. Dosen bisa melakukan evaluasi kinerja secara berkala sehingga kekurangan dalam proses pembelajaran dapat diperbaiki.

Banyak cara yang bisa dilakukan dalam melakukan evaluasi kinerja dosen untuk kegiatan pembelajaran di kelas. Pimpinan perguruan tinggi melalui ketua program studi juga melakukan evaluasi tersebut setiap semester. Namun, bagi 
Al-Ishlah: Jurnal Pendidikan - ISSN: 2087-949o (p); 2597-940X (e)

Vol. 12, No. 2 (2020)

dosen kegiatan evaluasi kinerja bisa dilakukan secara rutin setelah kegiatan pembelajaran melalui perspektif mahasiswa. kegiatan evaluasi kinerja tenaga pendidik bisa menggunakan penilaian yang dibuat oleh mahasiswa, rekan kerja, pimpinan, pengawas dan penilaian sendiri (Alicias, 2005). Artinya kegiatan evaluasi ini dilakukan dengan strategi pemantauan diri (self-monitoring). Pemantauan diri merupakan proses pengaturan diri seseorang dalam proses berpikir. Konteks pemantauan diri dalam penelitian ini fokus pada proses mengevaluasi hasil kinerja yaitu proses pembelajaran yang bisa memberikan pangaruh positif pada kegiatan belajar di kelas. Dengan menerapkan proses pemantauan diri, guru memperoleh pengetahuan lebih lanjut dalam pengukuran dan evaluasi pembelajaran, berpartisipasi dalam perencanaan tindakan, serta realisasi dan kesadaran yang lebih besar tentang pentingnya pengukuran dan evaluasi pembelajaran (Suknaisith, Wongwanich, \& Piromsombat, 2014).

Oleh karena itu, penelitian ini penting dilakukan untuk meningkatkan pemahaman proses pemantauan diri dalam konteks evaluasi kinerja dosen yang diperoleh dari hasil evaluasi mahasiswa di kelas. Selain itu, kegiatan evaluasi memberikan masukan yang bisa meningkatkan kualitas proses belajar mengajar. Banyak penelitian terdahulu yang telah dilakukan berkaitan dengan kegiatan evaluasi kinerja tenaga pendidik baik tentang hasil belajar mengajar di kelas ataupun kualitas diri dosen sendiri. Seperti penelitian yang dilakukan Harris \& Sass (2014) menyimpulkan bahwa kepala sekolah bisa membedakan antara guru yang memiliki kinerja tinggi dan rendah yangbisa berkontribusi terhadap prestasi siswa. Artinya bahwa kinerja guru memberikan pengaruh yang cukup signifikan terhadap hasil belajar mengajar. Dengan demikian, hasil evaluasi tersebut bisa memberikan motivasi positif pada tenaga pendidik (Cuevas, Ntoumanis, Fernandez-Bustos, \& Bartholomew, 2018). Dalam penelitian berbeda menunjukkan bahwa penilaian kinerja tidak selalu sama dalam situasi yang diharapkan (Barnett, 2012). Berbeda halnya dengan Atkinson, dkk (2009) yang mengkaji penilaian kinerja menggunakan skema kesejahteraan guru melalui pencapaian prestasi siswa. Hal ini menyimpulkan bahwa ada peningkatan nilai prestasi siswa dan tingkat kinerja guru. Hampir setiap negara bagian mengevaluasi kinerja guru menggunakan berbagai ukuran, tetapi bukti sebagian besar telah menunjukkan bahwa hanya satu ukuran tersebut tersebut yaitu efek guru pada prestasi siswa (yaitu, nilai tambah) dan hubungan interaktif antara guru dan siswa (Bacher-Hicks, Chin, Kane, \& Staiger, 2019).

Di Indonesia, konteks evaluasi kinerja yang ada di sekolah sering dilakukan dalam bentuk supervisi baik dilakukan oleh kepala sekolah ataupun pengawas. Hal ini cukup efektif dalam meningkatkan kualitas pembelajaran, kualitas sumber daya pengajar (dosen atau guru) ataupun kualitas penyelenggaraan pendidikan (Masliah, 2019; Ghufron \& Mubarok, 2018; Dewi, 
Al-Ishlah: Jurnal Pendidikan - ISSN: 2087-949o (p); 2597-940X (e)

Vol. 12, No. 2 (2020)

2018; Ariasa Giri, 2016). Jadi, model supervisi terhadap kinerja tenaga pendidik memberdayakan kapasitas tenaga pendidik, menghilangkan gangguan pengukuran kinerja, dan mengubah praktik ini menjadi misi eksplorasi mandiri. Dengan demikian, model supervisi dan evaluasi yang terpadu bisa memberikan pengaruh yang cukup besar terhadap penyelenggaraan pendidikan (Marey, Hesham, Magdd, $\&$ Toprak, 2020).

Dari beberapa penelitian tersebut dapat dipahami bahwa kegiatan evaluas kinerja mempunyai pengaruh yang besar terhadap suatu lembaga ataupun kualitas dosen atau tenaga. Kegiatan eavaluasi juga sering dilakukan oleh pimpinan organisasi terhadap bawahan. Namun, dalam kontek penelitian ini, evaluasi diri dilakukan melalui strategi pemantauan diri yang merujuk pada refleksi hasil kinerja sendiri yang dilakukan melalui perspektif ataupun pandangan mahasiswa terhadap hasil mengajar di kelas.

Oleh karena itu, tujuan dari penelitian ini adalah mengkaji lebih mendalam strategi pemantauan diri dosen dalam melakukan evaluasi kinerja sehingga dapat meningkatkan kualitas pendidikan. Dalam hal ini, evaluasi kinerja merujuk pada hasil proses belajar mengajar yang dilakukan oleh dosen. Hasil penelitian ini bisa memberikan manfaat terhadap pemahaman konsep pemantauan diri bagi dosen. Artinya bahwa dosen harus pandai melakukan refleksi diri dari hasil kinerjanya. Dengan demikian, dosen bisa memadukan hasil evaluasi kinerja dari pimpinan. Konsep ini memfasilitasi diri dosen bahwa evaluasi kinerja melalui selfmonitoring dapat membantu meningkatkan proses pengajaran.

\section{METODE PENELITIAN}

Pendekatan penelitian yang digunakan adalah penelitian kualitatif dengan metode deskriptif kualitatif. Penelitian kualitatif mengkaji berbagai fenomena yang terjadi di lapangan sesuai dengan fakta yang ditemukan (Ary, Jacobs, Sorensen, \& Razavieh, 2010). Dalam konteks penelitian yang dilakukan merujuk pada pengkajian strategi pemantauan diri yang digunakan oleh dosen untuk mengevaluasi kinerja (proses pembelajaran dan pengajaran) dari perspektif mahasiswa.

Teknik pengumpulan data menggunakan observasi, dan wawancara. Kegiatan observasi dilakukan dengan tujuan untuk mendapatkan informasi terkait dengan cara dosen melakukan evaluasi proses pengajaran yang dilakukan di akhir kelas. Sedangkan wawancara dilakukan untuk mendapatkan informasi lebih mendalam tentang implementasi strategi pemantauan diri dosen mengevaluasi kinerjanya. Wawancara dilakukan kepada dosen dan mahasiswa yang dilakukan secara tertutup. Artinya setiap informasi yang ingin diperoleh telah disiapkan melalui pertanyaan-pertanyaan yang telah disusun peneliti sebelum melakukan wawancara. Partisipan yang terlibat dalam penelitian ini adalah dosen sebanyak 3 orang dan mahasiswa sebanyak 15 yang menjadi subyek wawancara. Penelitian 
Al-Ishlah: Jurnal Pendidikan - ISSN: 2087-949o (p); 2597-940X (e)

Vol. 12, No. 2 (2020)

dilakukan di Institute Teknologi dan Bisnis Ahmad Dahlan Jakarta selama 3 bulan dari bulan September sampai November 2020. Adapun kisi-kisi untuk pertanyaan wawancara adalah rencana kerja (kegiatan pembelajaran dan pengajaran), melaksanakan tugas secara professional, melakukan evaluasi hasil pembelajaran dan sikap dan perilaku tanggung jawab.

Teknik analisis data dilakukan melalui tiga tahap (Miles \& Huberman, 1994). Pertama reduksi data yaitu penentuan dan pengkajian masalah yang ditemukan dengan data awal yang ditemukan serta mengumpulkan data penelitian sesuai kebutuhan fokus masalah penelitian. Kedua adalah penyajian data yaitu mengklasifikasikan atau mengkategorikan data yang telah diperoleh sesuai dengan kebutuhan dan melakukan analisis data secara mendalam. Ketiga adalah penarikan simpulan dan verifikasi data yang telah dianalisis.

\section{HASIL DAN PEMBAHASAN}

Data yang telah diperoleh dari hasil wawancara dengan mahasiswa dan dosen dianalisis dan diinterpretasikan oleh peneliti untuk dapat simpulan yang sesuai dengan data. Adapun simpulan analisis data wawancara disajikan pada tabel berikut ini.

Tabel 1 Simpulan Analisis Data Wawancara Dengan Mahasiswa dan Dosen

\begin{tabular}{llll}
\hline No & $\begin{array}{c}\text { Indikator } \\
\text { Kinerja }\end{array}$ & \multicolumn{2}{c}{ Hasil Analisis Data Wawancara } \\
\hline 1 & Menyusun \\
rencana kerja & $\begin{array}{l}\text { Dosen telah menyusun rencana pembelajaran sebelum } \\
\text { melaksanakan pembelajaran di kelas setiap semester yang } \\
\text { disesuaikan dengan perkembangan kebutuhan global }\end{array}$
\end{tabular}

Dosen telah menyusun rencana pembelajaran berdasarkan kurikulum yang berlaku di Universitas dan disesuaikan dengan tingkat kebutuhan pencapaian tujuan pembelajaran di program studi.

Dosen telah menyusun materi pembelajaran sesuai tingkat dan semester serta tujuan yang telah ditetapkan oleh program studi untuk mencapai visi misi Universitas

Dosen biasanya menggunakan strategi pembelajaran sesuai materi pembelajaran. Strategi pembelajaran dilakukan secara bervariasi sesuai dengan karakteristik mahasiswa.

Dosen menyiapkan media pendukung pembelajaran sebelum melaksanakan proses belajar mengajar di kelas yang berbeda sesuai mata kuliah dan setiap semester memiliki media belajar yang berbeda sesuai dengan masukkan dari mahasiswa.

2 Melaksanakan Dosen menggunakan metode pembelajaran secara bervariatif tugas secara agar proses pembelajaran menjadi menarik berdasarkan pada profesional hasil masukkan mahasiswa di akhir pembelajaran. 
Al-Ishlah: Jurnal Pendidikan - ISSN: 2087-949o (p); 2597-940X (e)

Vol. 12, No. 2 (2020)

Dosen memperhatikan perbedaan individu siswa untuk keberhasilan dalam proses pembelajaran di kelas. Dosen melakukan pemetaan karakteristik mahasiswa setiap semester yang disesuaikan latar belakang mahasiswa serta pengalaman belajar mahasiswa.

Strategi pembelajaran yang digunakan telah sesuai hasil analisis karakteristik mahasiswa serta kebutuhan dari tujuan pembelajaran yang ingin dicapai.

Dosen mengajar sesuai bidang keilmuan dan selalu melakukan pembaharuan pengetahuan yang terus berkembang.

Dosen menciptakan lingkungan belajar yang kondusif untuk memudahkan mahasiswa dalam memahami materi pelajaran.

$3 \quad$ Evaluasi proses Dosen memberikan hasil penilaian terhadap tugas-tugas belajar di kelas mahasiswa walaupun kadang tidak setiap tugas diberikan feedback dan dosen melakukan kegiatan penilaian sejawat yang dilakukan $3 x$ dala satu semester.

Dosen memberikan nilai secara obyektif pada hasil belajar mahasiswa

Dosen menggunakan hasil belajar mahasiswa sebagai bahan evaluasi diri dalam mengajar

Dosen menggunakan data hasil belajar mahasiswa sebagai alat ukur kemajuan belajar mahasiswa

Dosen memberikan bimbingan belajar khusus terhadap mahasiswa yang hasil belajarnya rendah

$4 \quad$ Sikap dan perilaku tanggung jawab

Dosen mencatat kegiatan pembelajaran yang telah dilaksanakan setiap pertemuan belajar selesai

Dosen masuk kelas mengajar tepat waktu walaupun beberapa pertemuan masuk terlambat

Dosen melaporkan hasil belajar mahasiswa secara berkala kepada mahasiswa ataupun setiap semester kepada program studi.

Dosen memberikan kesempatan kepada mahasiswa yang ingin memperbaiki nilai, bertanya ataupun melakukan diskusi di luar kelas

Dosen melaksanakan setiap tugas mengajar sesuai dengan ketentuan yang telah ditetapkan oleh Universitas dan 
Al-Ishlah: Jurnal Pendidikan - ISSN: 2087-949o (p); 2597-940X (e)

Vol. 12, No. 2 (2020)

menciptakan suasana belajar yang menyenangkan

Dosen telah melakukan rencana kerja yang terencana dan tersusun secara sistematis sesuai dengan waktu yang telah ditetapkan. Hal-hal krusial yang terkait dengan evaluasi penggunaan kurikulum telah diperhatikan dengan perkembangan keilmuan dan tuntutan global saat ini, sehingga penetapan tujuan pembelajaran bisa membekali mahasiswa dalam menghadapi era globalisasi. Dosen juga telah melaksanakan tugas mengajar secara professional. Hal ini diketahui dari perancangan materi, penggunaan media belajar dan juga strategi belajar yang sesuai dengan kebutuhan mata kuliah serta karakteristik mahasiswa. Artinya strategi harus bervariasi agar tidak menimbulkan kejenuhan ataupun salah sasaran. Apalagi setiap mahasiswa memiliki kepribadian berbeda serta kemampuan berbeda dalam menyerap materi. Jadi, dosen telah menunjukkan kinerja professional.

Kompetensi profesional dosen baik meliputi pengetahuan, keterampilan, keyakinan, dan motivasi profesional mereka merupakan prediktor penting bagi kesejahteraan dan kesuksesan profesional kerja (Lauermann \& König, 2016). Jika dosen sudah professional dalam kerja, maka kompetensi seperti pedagogik juga mendukung kinerjanya dalam melakukan proses belajar mengajar. Tenaga pendidik mempunyai kemampuan yang baik dalam mengatur materi pembelajaran yang sesuai dengan kebutuhan mahasiswa serta penggunaan strategi belajar yang tepat (Rahman, 2014). Pada penelitian Tyagita \& Iriani (2018) menunjukkan 6 rencana strategis untuk meningkatkan kompetensi pedagogik guru dengan mengedepankan kerjasama antara guru, siswa dan juga orang tua. Kolaborasi dibangun dengan sangat optimal dalam melaksanakan tugas.

Dengan demikian, pendidikan yang diciptakan oleh dosen bisa memberikan pembangunan berkelanjutan. Seperti yang dicanangkan oleh Perserikatan Bangsa-Bangsa yang telah menganjurkan bahwa semua pelajar akan memiliki pengetahuan dan keterampilan yang dibutuhkan untuk mempromosikan pembangunan berkelanjutan (O'Flaherty \& Liddy, 2018). Dari hasil penelitian ini dapat diselaraskan dengan hasil temuan dalam penelitian ini bahwa sikap professional dosen dalam mengajar memberikan dampak terhadap pembangunan pendidikan yang berkelanjutan. Selain itu, hal ini juga bisa berdampak pada pembangunan indek kualitas manusia yang mampu mengembangkan kehidupan lebih maju.

Profesionalisme dosen harus sesuai dengan UU No.14 Tahun 2005 tentang Guru dan Dosen yang telah menetapkan bahwa tenaga pendidik sebagai tenaga profesi harus memiliki empat kompetensi dasar agar mampu menghasilkan proses pembelajaran dan pengajaran yang berkulitas. Kompetensi tersebut adalah kompetensi pedagogik, kompetensi kepribadian, kompetensi sosial, dan 
Al-Ishlah: Jurnal Pendidikan - ISSN: 2087-949o (p); 2597-940X (e)

Vol. 12, No. 2 (2020)

kompetensi professional. Dari hasil data wawancara dan observasi, dosen di Institute Teknologi dan Bisnis Ahmad Dahlan pada program studi Manajemen Pendidikan telah menunjukkan sikap seorang professional. Hasil evaluasi diri yang dilakukan secara rutin setiap semester. Selain itu, evaluasi kinerja yang berkaitan dengan hasil proses pembelajaran pengajaran dilakukan setiap selesai mengajar. Artinya dosen berupaya untuk selalu mengetahui kekurangan dalam mengajar baik dari implementasi strategi pembelajaran ataupun materi yang diberikan kepada mahasiswa. Proses pemantauan diri yang telah dilakukan dosen dalam melakukan evaluasi kinerja mereka sudah sangat baik. Jadi, dosen sudah memahami bagaimana membangun kinerja untuk memenuhi kebutuhan dan tantangan dari kehidupan di kota serta perkembangan global. Kualitas dosen adalah kunci pencapaian prestasi mahasiswa dan keberhasilan lembaga pendidikan. Kinerja dosen juga sangat dipengaruhi oleh pengaturan suasana akademik lembaga pendidikan tinggi (Kuriloff, Jordan, Sutherland, \& Ponnock, 2019).

\section{SIMPULAN}

Dari hasil analisis data disimpulkan bahwa dosen telah melakukan kegiatan evaluasi kinerja yaitu hasil proses belajar mengajar di kelas secara teratur dan sistematis. Dosen menggunakan waktu evaluasi dengan sangat tepat yaitu diakhir semester yang bertujuan untuk mengetahui keseluruhan hasil kinerja selama satu semester. Dosen membandingkan hasil evaluasi diri sendiri dengan hasil evaluasi dari program studi. Evaluasi yang dilakukan dosen sesuai dengan masukan dari mahasiswa. Selain itu, evaluasi kinerja juga tetap dilakukan disetiap akhir pertemuan dari proses belajar mengajar sehingga setiap pertemuan dosen menciptakan suasana pembelajaran yang berbeda dan memberikan rasa nyaman untuk belajar.

Penelitian ini berimplikasi pada sistem evaluasi kinerja untuk Universitas baik sistem yang harus dimiliki oleh dosen sendiri dalam melakukan evaluasi hasil kerjanya sendiri ataupun universitas. Dari hasil kajian menunjukkan bahwa dosen telah membuat sistem evaluasi kinerja dengan strategi pemantauan diri yang dipadukan pada hasil evaluasi dari universitas. Namun, penelitian ini masih banyak kekurangan dan keterbatasan. Keterbatasan penelitian ini terlihat pada jumlah partisipan sebagai subyek penelitian ataupun informan masih sedikit serta waktu peneltian yang dilakukan dengan singkat. Oleh karena itu, penelitian ini masih bisa dilanjutkan dengan penelitian pengembangan sistem evaluasi kinerja di lembaga pendidikan. Bagi para peneliti yang ingin melakukan penelitian dengan tema yang sama bisa memperhatikan waktu penelitian dan jumlah informan, serta mengembangkan fokus penelitian yang bisa diterapkan di perguruan tinggi seperti penciptaan lingkungan ataupun suasana akademik khususnya di kelas dari hasil evaluasi diri dosen. 
Al-Ishlah: Jurnal Pendidikan - ISSN: 2087-949o (p); 2597-940X (e)

Vol. 12, No. 2 (2020)

\section{DAFTAR PUSTAKA}

Alicias, E. R. (2005, May 6). Toward an objective evaluation of teacher performance: The use of variance partitioning analysis, VPA. Education Policy Analysis Archives. Arizona State University. https://doi.org/10.14507/epaa.v13n30.2005

Ariasa Giri, I. M. (2016). SUPERVISI PENDIDIKAN DALAM PENINGKATAN MUTU PENDIDIKAN DI SEKOLAH. Jurnal Penjaminan Mutu, 2(1), 44. https://doi.org/10.25078/jpm.v2i1.60

Ary, D., Jacobs, L. C., Sorensen, C., \& Razavieh, A. (2010). Introduction to Research in Education (8 Edition). CA: Cengage Learning.

Atkinson, A., Burgess, S., Croxson, B., Gregg, P., Propper, C., Slater, H., \& Wilson, D. (2009). Evaluating the impact of performance-related pay for teachers in England. Labour Economics, 16(3), 251-261. https://doi.org/10.1016/j.labeco.2008.10.003

Bacher-Hicks, A., Chin, M. J., Kane, T. J., \& Staiger, D. O. (2019). An experimental evaluation of three teacher quality measures: Value-added, classroom observations, and student surveys. Economics of Education Review, 73, 101919. https://doi.org/10.1016/j.econedurev.2019.101919

Barnett, J. A. (2012). Experienced Teacher Evaluation through Performance Appraisals: Is Consistency Possible? Procedia - Social and Behavioral Sciences, 69, 1853-1860. https://doi.org/10.1016/j.sbspro.2012.12.137

Cuevas, R., Ntoumanis, N., Fernandez-Bustos, J. G., \& Bartholomew, K. (2018). Does teacher evaluation based on student performance predict motivation, well-being, and ill-being? Journal of School Psychology, 68, 154-162. https://doi.org/10.1016/j.jsp.2018.03.005

Dewi, C. (2018). MANAJEMEN PENGEMBANGAN KOMPETENSI DOSEN. JMSP: Jurnal Manajemen Dan Supervisi Pendidikan, 3(1).

Ghufron, A., \& Mubarok, H. (2018). SUPERVISI AKADEMIK SEBAGAI DASAR PENGEMBANGAN PEMBELAJARAN GURU. ELEMENTARY, 4(2). https://doi.org/10.21043/elementary.v4i2.3000

Harris, D. N., \& Sass, T. R. (2014). Skills, productivity and the evaluation of teacher performance. Economics of Education Review, 40, 183-204. https://doi.org/10.1016/j.econedurev.2014.03.002

Kuriloff, P., Jordan, W., Sutherland, D., \& Ponnock, A. (2019). Teacher preparation and performance in high-needs urban schools: What matters to teachers. Teaching and Teacher Education, 83, 54-63. https://doi.org/10.1016/j.tate.2019.04.001

Lauermann, F., \& König, J. (2016). Teachers' professional competence and wellbeing: Understanding the links between general pedagogical knowledge, self-efficacy and burnout. Learning and Instruction, 45, 9-19. 
Al-Ishlah: Jurnal Pendidikan - ISSN: 2087-949o (p); 2597-940X (e)

Vol. 12, No. 2 (2020)

https://doi.org/10.1016/J.LEARNINSTRUC.2016.06.006

Marey, R., Hesham, G., Magdd, A., \& Toprak, M. (2020). Re-conceptualizing teacher evaluation and supervision in the light of educational reforms in Egypt. Social Sciences \& Humanities Open, 2(1), 100081. https://doi.org/10.1016/j.ssaho.2020.100081

Masliah, E. (2019). Pengembangan Model Supervisi Akademik Teknik Mentoring dalam Upaya Peningkatan Mutu Pembelajaran. Indoensian Journal of Educational Management \& Administration Review, 3(2).

Miles, M. B., \& Huberman, A. M. (1994). Qualitative Data Analysis; An Expanded Sourcebook. New Delhi: Sage Publication.

O'Flaherty, J., \& Liddy, M. (2018). The impact of development education and education for sustainable development interventions: a synthesis of the research. Environmental Education Research, 24(7), 1031-1049. https://doi.org/10.1080/13504622.2017.1392484

Rahman, M. H. (2014). Professional Competence, Pedagogical Competence and the Performance of Junior High School of Science Teachers. Journal of Education and Practice, 5(9), 75-80. Retrieved from www.iiste.org

Skovholt, K., Nordenström, E., \& Stokoe, E. (2019). Evaluative conduct in teacher-student supervision: When students assess their own performance. Linguistics and Education, 50, 46-55. https://doi.org/10.1016/j.linged.2019.03.001

Suknaisith, A., Wongwanich, S., \& Piromsombat, C. (2014). Development of Teacher Performance in Educational Measurements and Evaluation through Self-monitoring Strategies. Procedia - Social and Behavioral Sciences, 116, 1683-1688. https://doi.org/10.1016/j.sbspro.2014.01.456

Tyagita, B. P. A., \& Iriani, A. (2018). Strategi Peningkatan Kompetensi Pedagogik Guru Untuk Meningkatkan Mutu Sekolah. Kelola: Jurnal Manajemen Pendidikan, 5(2), 165-176. https://doi.org/10.24246/j.jk.2018.v5.i2.p165-176 